\title{
Penetração de cloretos em concretos expostos em zona de atmosfera marinha por um período de 9 anos
}

\author{
Chloride penetration in concretes exposed in a marine \\ atmosphere zone for a period of 9 years
}

\section{Laura Silvestro \\ Fátima Sequeira Romano \\ Denise Carpena Coitinho Dal Molin}

Resumo

corrosão de armaduras é a manifestação patológica mais recorrente em estruturas de concreto armado, despertando maior preocupação em regiões litorâneas devido à presença de íons cloreto. Isso posto, destaca-se a carência de dados da concentração de cloretos de concretos em condição natural de exposição, principalmente na zona de atmosfera marinha. Dessa forma, este trabalho teve como objetivo avaliar os perfis de cloretos de blocos de concreto moldados com teores de substituição de sílica ativa de 5\% (CP V_5SA) e 10\% (CP V_10SA) quanto à massa de cimento e a relações a/agl de $0,45,0,55$ e 0,65 . Os concretos permaneceram expostos em zona de atmosfera marinha por um período de 9 anos na cidade de Tramandaí, Rio Grande do Sul. Inicialmente, foram retiradas amostras pulverulentas dos blocos de concreto para posterior determinação da concentração de cloretos solúveis em água. No tocante à corrosão de armaduras, a utilização de teores de sílica ativa em percentuais de 5\% e $10 \%$ é eficiente na redução do ingresso de cloretos; baixas relações a/agl apresentaram concentrações superficiais mais elevadas, em contrapartida, à medida que a profundidade em relação à superfície do concreto aumenta, há uma redução nesses teores. Além disso, o trabalho evidenciou que a redução da relação a/agl e a incorporação de sílica ativa se mostraram medidas eficazes na redução da concentração de cloretos ao longo do tempo.

Palavras-chave: Corrosão de armaduras. Cloretos. Zona de atmosfera marinha.

\section{Abstract}

Corrosion in reinforced concrete structures is the most recurrent pathological manifestation in concrete structures, causing greater concern in coastal regions due to the presence of chloride ions. That said, there is a notable lack of data on the chloride concentration of concrete in natural conditions of exposure, especially in the marine atmosphere zone. Hence, this study aimed to evaluate the chloride profiles of concrete blocks molded with silica fume contents of 5\% (CP V_5SA) and 10\% (CP V_10SA) in relation to cement mass and $w / b$ ratios of $0.45,0.55$ and 0.65 . The concretes remained exposed in a marine atmosphere zone for a period of 9 years in Tramandaí, Rio Grande do Sul, Brazil. Powder samples were taken from the concrete blocks for further determination of the water-soluble chloride concentration. With regards to corrosion, the use of silica fume content in percentages of $5 \%$ and $10 \%$ is efficient in reducing chloride penetration; low w/b ratios showed higher surface concentrations. However, as the depth of the concrete surface increases, there is a reduction in these contents. In addition, the study showed that the reduction of the $w / b$ ratio and the incorporation of silica fume were effective measures in reducing the concentration of chlorides over time.

Keywords: Corrosion in reinforced concrete. Chlorides. Marine atmosphere zone. 


\section{Introdução}

Entre os mecanismos de degradação que afetam a vida útil das estruturas de concreto armado, a corrosão de armaduras é um dos mais frequentes (BRANDÃO, 2007; MILANI; KRIPKA, 2012; MUTHULINGAM; RAO, 2015; PINTAN et al., 2015; SILVA; CABRAL, 2014; WEERDT et al., 2016), sendo responsável por grande parte dos danos nessas estruturas. Esses danos manifestam-se na forma de manchas superficiais, seguidas por fissuras, destacamento do concreto de cobrimento, redução da seção e perda de aderência das armaduras principais (RIBEIRO et al., 2014), podendo levar ao comprometimento da segurança estrutural ao longo do tempo (SHODJA; KIANI; HASHEMIAN, 2010). Os produtos formados no processo corrosivo são expansivos e induzem ao aumento das tensões no interior do concreto, resultando em sua deterioração, o que contribui para a drástica redução da vida útil dessas estruturas (RIBEIRO et al., 2014; TUUTTI, 1982).

A problemática de degradação de estruturas de concreto armado devido à corrosão de armaduras desperta maior preocupação em regiões costeiras, em razão da elevada agressividade desse ambiente provocada pela presença de cloretos. Como agravante, a extensão da costa brasileira é de 7.367 km (INSTITUTO..., 2017) e muitas das capitais brasileiras estão ali localizadas, tais como Fortaleza, Natal, João Pessoa, Recife, Maceió, Salvador, Vitória, Rio de Janeiro e Florianópolis.

Em grande parte dos estudos que avaliam o comportamento do concreto armado diante da ação de cloretos, o processo corrosivo é acelerado aplicando-se uma corrente externa (OTIENO; BEUSHAUSEN; ALEXANDER, 2014; SPIESZ; BROUWERS, 2013; TORRES-ACOSTA; NAVARRO-GUTIERREZ; TERÁN-GUILLÉN, 2007; YILDIRIM; ILICA; SENGUL, 2011), adicionando substâncias como o $\mathrm{CaCl}_{2}$ ou o NaCl na mistura do concreto (LIU et al., 2016; OH; JANG, 2007; PRUCKNER; GJORV, 2004; XU et al., 2011) ou através de ciclos de molhagem e secagem com soluções de $\mathrm{NaCl}$, uma vez que não se dispõe do tempo necessário para que o fenômeno ocorra de forma natural.

Esses ensaios acelerados recebem algumas críticas porque são caracterizados pela aplicação de condições bastante agressivas, que visam minimizar o tempo para a obtenção dos resultados e que usualmente não condizem com as reais condições de exposição ao fenômeno natural. Isso porque, segundo Andrade (2001), o ajuste das intensidades dos agentes agressivos necessários para provocar a aceleração dos danos pode vir a distorcer os resultados obtidos. Dessa maneira, tais ensaios normalmente são utilizados para analisar comparativamente o desempenho de diferentes materiais (DAL MOLIN et al., 2016).

Meira et al. (2007) citam que, no geral, as condições de laboratório não reproduzem com precisão as reais condições de exposição, em que os parâmetros que influenciam a penetração de cloretos no concreto atuam simultaneamente. Adicionalmente, Andrade (2001) destaca que os ensaios acelerados diferem das reais condições de exposição, principalmente no tocante às oscilações ambientais.

Nesse contexto, Meira e Ferreira (2019) mencionam que existem aspectos que distanciam os ensaios acelerados das condições reais de exposição, uma vez que há uma multiplicidade de ações que ocorre de forma simultânea e aleatória em ambientes naturais. Contudo, como a obtenção de resultados em ensaios em condições naturais de exposição pode demandar períodos de tempo longos e maiores custos operacionais, o que do ponto de vista prático pode inviabilizar seu emprego de forma regular, faz-se necessário utilizar ensaios acelerados que se aproximem das condições naturais de exposição ou fatores de correção para esse fim. Porém, embora tenha havido uma evolução nos procedimentos adotados para os ensaios acelerados no que tange à penetração de íons cloreto no concreto, ainda não há uma padronização amplamente praticada nas pesquisas, o que também representa um desafio para a aplicação desses métodos de ensaio em relação às condições naturais de exposição (MEIRA; FERREIRA, 2019).

Além disso, deve-se considerar que, como as condições de exposição diferem de um local para outro em função das características climáticas e de salinidade, para projetar e avaliar a vida útil de estruturas de concreto em determinada localização, são necessários dados de entrada de penetração de cloretos já existentes obtidos no mesmo local de exposição (PANG; LI, 2016). Isso posto, reitera-se a importância da realização dos ensaios em condições naturais de exposição, bem como da compilação dos dados de penetração de cloretos em estruturas de concreto existentes em um banco de dados.

Nesse âmbito, alguns estudos vêm sendo realizados em ambientes marítimos, com condições de exposição naturais (CHALEE; JATURAPITAKKUL; CHINDAPRASIRT, 2009; DASAR et al., 2017; MARIC et al., 2017; VALIPOUR et al., 2013). Esses estudos são considerados mais adequados para avaliar a penetração de íons cloreto no concreto e prever a vida útil desse tipo de estrutura, apesar de demandarem períodos de exposição superiores aos necessários em ensaios acelerados. Apesar disso, Pang e Li (2016) destacam que usualmente os dados existentes relativos à penetração de cloretos em concretos em exposição natural são 
oriundos de amostras expostas por períodos relativamente curtos, o que, do ponto de vista de previsão de vida útil, dificulta a modelagem do ingresso de cloretos ao longo de elevados períodos de exposição.

Tendo em vista que grande parte dos dados de penetração de cloretos existentes na literatura foi obtida através de ensaios acelerados e considerando a importância de dados reais da penetração de cloretos em concretos expostos em zona de atmosfera marinha, este trabalho teve como objetivo a determinação do perfil de cloretos de concretos expostos por um período de 9 anos em zona de atmosfera marinha, na cidade de Tramandaí, litoral no Rio Grande do Sul. Além disso, destaca-se que a zona de atmosfera marinha, do ponto de vista da agressividade marinha, em comparação às zonas de respingos e variação de maré, é menos danosa às estruturas de concreto, o que justifica o pequeno número de trabalho dedicado a essa zona (MEIRA, 2004) e evidencia a importância do trabalho em questão.

\section{Materiais e métodos}

\section{Caracterização dos materiais empregados}

Foi utilizado o cimento Portland de alta resistência inicial (CP V - ARI) para a moldagem dos blocos de concreto. Nas Tabelas 1 e 2 são apresentados os resultados das caracterizações química e física fornecidos pelo fabricante, bem como as exigências estabelecidas pela norma NBR 5733 (ABNT, 1991) correspondente ao cimento CP V - ARI.

A caracterização da sílica ativa utilizada, fornecida pelo fabricante do produto, é apresentada na Tabela 3. A sílica foi incorporada nos concretos em percentuais de substituição de 5\% e $10 \%$ em relação à massa de cimento Portland.

Foi utilizada uma areia quartzosa de origem natural como agregado miúdo. A areia apresenta dimensão máxima característica de 4,8 mm (ABNT, 2003a), módulo de finura de 2,72 (ABNT, 2003a) e massa específica de 2,62 $\mathrm{g} / \mathrm{cm}^{3}$ (ABNT, 2009a).

Já o agregado graúdo empregado foi uma pedra britada de origem basáltica, com dimensão máxima característica de $19 \mathrm{~mm}$ (ABNT, 2003a), módulo de finura de 6,84 (ABNT, 2003a) e massa específica de $2,72 \mathrm{~g} / \mathrm{cm}^{3}$ (ABNT, 2009b).

Tabela 1 - Caracterização química do cimento e exigências normativas

\begin{tabular}{c|c|c}
\hline Propriedades químicas & Resultados & Exigências normativas \\
\hline $\mathrm{Al}_{2} \mathrm{O}_{3}$ & 4,79 & - \\
$\mathrm{SiO}_{2}$ & 19,59 & - \\
$\mathrm{Fe}_{2} \mathrm{O}_{3}$ & 3,07 & - \\
$\mathrm{CaO}$ & 64,35 & - \\
$\mathrm{MgO}$ & 1,69 & $\leq 6,5$ \\
$\mathrm{SO}_{3}$ & 2,75 & $\leq 3,5$ \\
Perda ao fogo & 2,09 & $\leq 4,5$ \\
$\mathrm{CaO}$ livre & 1,02 & - \\
Resíduo Insolúvel & 0,46 & $\leq 1,0$ \\
\hline
\end{tabular}

Fonte: Romano (2009).

Tabela 2 - Caracterização física do cimento e exigências normativas

\begin{tabular}{c|c|c}
\hline Propriedades físicas & Resultados & Exigências normativas \\
\hline Massa específica $\left(\mathrm{g} / \mathrm{cm}^{3}\right)$ & 3,1 & - \\
Blaine $\left(\mathrm{cm}^{2} / \mathrm{g}\right)$ & $4.230,0$ & $\geq 3.000$ \\
Tempo de início de pega $(\mathrm{min})$ & 134,0 & $\geq 60$ \\
Tempo de fim de pega $(\mathrm{min})$ & 195,0 & $\leq 600$ \\
Finura peneira \#200 $(\%)$ & 0,1 & $\leq 6$ \\
Expansibilidade $(\mathrm{mm})$ & 0,0 & $\leq 5$ \\
Resistência à compressão 3 dias $(\mathrm{MPa})$ & 35,1 & $\geq 24$ \\
Resistência à compressão 7 dias $(\mathrm{MPa})$ & 41,2 & $\geq 34$ \\
Resistência à compressão 28 dias $(\mathrm{MPa})$ & 49,6 & - \\
\hline
\end{tabular}

Fonte: Romano (2009). 
Tabela 3 - Caracterização química e física da sílica ativa

\begin{tabular}{|c|c|}
\hline Elementos químicos & Teor $(\%)$ \\
\hline $\mathrm{Al}_{2} \mathrm{O}_{3}$ & 0,09 \\
\hline $\mathrm{SiO}_{2}$ & 95,10 \\
\hline $\mathrm{Fe}_{2} \mathrm{O}_{3}$ & 0,10 \\
\hline $\mathrm{CaO}$ & 0,24 \\
\hline $\mathrm{MgO}$ & 0,44 \\
\hline $\mathrm{K}_{2} \mathrm{O}$ & 0,98 \\
\hline $\mathrm{Na}_{2} \mathrm{O}$ & 0,22 \\
\hline Perda ao fogo $(\%)$ & 2,32 \\
\hline Massa específica $\left(\mathrm{kg} / \mathrm{cm}^{3}\right)$ & 2,22 \\
\hline Superfície específica $\left(\mathrm{m}^{2} / \mathrm{g}\right)$ & 14,20 \\
\hline $\mathrm{pH}$ & 8,48 \\
\hline Umidade $(\%)$ & 0,67 \\
\hline
\end{tabular}

Fonte: Romano (2009).

Também foi utilizado um aditivo superplastificante de terceira geração à base de éter policarboxílico modificado. Este apresentava pH entre 5-7, densidade entre 1,067-1,107 g/cm³ e teor de sólidos de 38,0$42,0 \%$.

\section{Dosagem dos concretos}

Para a dosagem dos concretos, foi empregado o método IPT/EPUSP (HELENE; TERZIAN, 1993). Inicialmente, determinou-se o teor ideal de argamassa. Para o traço de 1:5,0, o teor de argamassa ideal obtido foi de 51\%. Fixando o abatimento do tronco de cone em $80 \mathrm{~mm} \pm 10 \mathrm{~mm}$ (ABNT, 1996) e considerando o teor de argamassa ideal de $51 \%$, também foram executados dois traços auxiliares: um traço rico $(1: 3,5)$ e outro pobre $(1: 6,5)$. Após a obtenção dos diagramas de dosagem, foram determinados os traços finais dos concretos moldados na pesquisa, considerando as relações a/agl de 0,45, 0,55 e 0,65, conforme consta na Tabela 4.

Foram moldados blocos de concreto com dimensões de $20 \mathrm{~cm}$ x $60 \mathrm{~cm}$ x $10 \mathrm{~cm}$ e corpos de prova cilíndricos de $9,5 \mathrm{~cm}$ x $19 \mathrm{~cm}$ para a realização do ensaio de resistência à compressão aos 3, 7 e 28 dias. Para cada traço avaliado, foi confeccionado um bloco de concreto e dois corpos de prova por idade para o ensaio de resistência à compressão. Após a concretagem, os blocos de concreto foram mantidos no ambiente de laboratório, cobertos com lona plástica por 48 horas e, posteriormente, desmoldados. A seguir, os blocos foram devidamente identificados e levados à câmara úmida, conforme especificado pela NBR 5738 (ABNT, 2003b), em que permaneceram por 7 dias e, posteriormente, foram posicionados na estação de monitoramento. Esse período de 7 dias foi adotado para representar de forma mais aproximada a cura que usualmente ocorre em estruturas de concreto reais.

A cura dos corpos de prova cilíndricos foi realizada de acordo com a NBR 5738 (ABNT, 2003b). Transcorridas 24 horas após a concretagem, efetuou-se a desmoldagem dos corpos de prova, os quais permaneceram em câmara úmida até a data de realização do ensaio de resistência à compressão nas idades preestabelecidas. $\mathrm{O}$ ensaio de resistência à compressão foi realizado de acordo com o preconizado na NBR 5739 (ABNT, 2007).

\section{Caracterização ambiental da estação de monitoramento}

Os blocos de concreto permaneceram expostos em zona de atmosfera marinha em uma estação de monitoramento na cidade de Tramandaí, localizada no estado do Rio Grande do Sul. Na Tabela 5 são apresentadas as coordenadas geográficas desse local de exposição e a distância desse ponto em relação ao mar. A Figura 1 apresenta a disposição dos blocos de concreto na referida estação de monitoramento.

É importante destacar que os blocos foram posicionados voltados para a direção nordeste, por se tratar da direção dos ventos predominantes da região, conforme previamente constatado no levantamento das características ambientais da região. Dessa forma, as análises realizadas nesta pesquisa contemplam apenas as faces dos blocos de concreto voltadas para a direção predominante dos ventos, ou seja, a nordeste.

104 Silvestro, L.; Romano, F. S.; Dal Molin, D. C. C. 
Tabela 4 - Traços dos blocos de concretos

\begin{tabular}{|c|c|c|c|c|c|c|}
\hline Traço & $\begin{array}{c}\text { Cimento } \\
\left(\mathrm{kg} / \mathrm{m}^{3}\right)\end{array}$ & $\begin{array}{c}\text { Sílica ativa } \\
\left(\mathrm{kg} / \mathrm{m}^{3}\right)\end{array}$ & $\begin{array}{c}\text { Areia } \\
\left(\mathrm{kg} / \mathrm{m}^{3}\right)\end{array}$ & $\begin{array}{c}\text { Brita } \\
\left(\mathrm{kg} / \mathrm{m}^{3}\right)\end{array}$ & $\begin{array}{c}\text { Aditivo } \\
(\%)\end{array}$ & $\begin{array}{c}\text { Abatimento } \\
\text { (mm) }\end{array}$ \\
\hline $\mathrm{CP} V-\mathrm{a} / \mathrm{agl}=0,45$ & 399,8 & 0,0 & 747,7 & $11031.103,4$ & 0,4 & 90 \\
\hline $\mathrm{CP} \mathrm{V}-\mathrm{a} / \mathrm{agl}=0,55$ & 331,0 & 0,0 & 807,7 & $1.095,0$ & 0,2 & 100 \\
\hline $\mathrm{CP} V-\mathrm{a} / \mathrm{agl}=0,65$ & 282,1 & 0,0 & 852,1 & $1.088,9$ & 0,1 & 95 \\
\hline CP V_5SA - a/agl $=0,45$ & 379,8 & 20,0 & 747,7 & $1.103,4$ & 0,5 & 85 \\
\hline $\mathrm{CP}$ V_5SA - a/agl $=0,55$ & 314,5 & 16,5 & 807,7 & $1.095,0$ & 0,4 & 90 \\
\hline CP V_5SA - a/agl $=0,65$ & 268,0 & 14,1 & 852,1 & $1.088,9$ & 0,2 & 95 \\
\hline CP V_10SA - a/agl $=0,45$ & 359,8 & 40,0 & 747,7 & $1.103,4$ & 0,6 & 80 \\
\hline CP V_10SA - a/agl $=0,55$ & 297,9 & 33,1 & 807,7 & $1.095,0$ & 0,4 & 85 \\
\hline CP V_10SA - a/agl $=0,65$ & 253,9 & 28,2 & 852,1 & $1.088,9$ & 0,2 & 95 \\
\hline
\end{tabular}

Fonte: Romano (2009).

Tabela 5 - Localização da estação de monitoramento de Tramandaí

\begin{tabular}{c|c|c|c}
\hline $\begin{array}{c}\text { Estação de } \\
\text { monitoramento }\end{array}$ & Latitude & Longitude & $\begin{array}{c}\text { Distância da } \\
\text { praia (m) }\end{array}$ \\
\hline $\mathrm{EM}-\mathrm{I}$ & $30^{\circ} 00^{\prime} 33^{\prime \prime} \mathrm{S}$ & $50^{\circ} 08^{\prime} 06^{\prime \prime} \mathrm{W}$ & 100 \\
\hline
\end{tabular}

Fonte: Romano (2009).

Figura 1 - Disposição dos blocos de concreto na estação de monitoramento

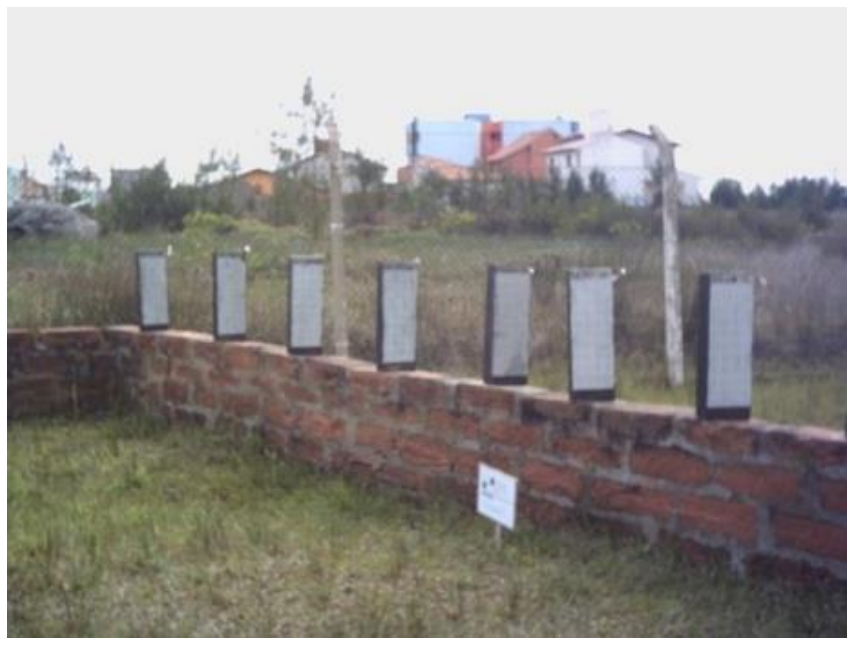

Fonte: Romano (2009).

Para a caracterização ambiental do local de exposição, foram coletados os seguintes dados: temperatura máxima, mínima e média; umidade relativa média; precipitação e direção e intensidade dos ventos referentes ao período de exposição, compreendido entre setembro de 2008 e outubro de 2017. Na caracterização da estação de monitoramento, foram utilizados os dados fornecidos pelo Instituto Nacional de Meteorologia (INMET) da Estação Meteorológica de Observação de Superfície Automática de Tramandaí - A834. Na Tabela 6 constam as coordenadas geográficas dessa estação. Destaca-se a proximidade entre as estações de monitoramento e meteorológica.

\section{Determinação do perfil de cloretos dos blocos de concreto}

\section{Extração de amostras dos blocos}

Foram extraídas amostras sob a forma pulverulenta da face nordeste de todos os blocos de concreto. Para isso, foi utilizado um martelete da marca Bosh, modelo GBH 2-24 DSE, com broca de $12 \mathrm{~mm}$. Seguindo o mesmo procedimento adotado por Romano (2009), foi desenhado um reticulado com espaçamento de $5 \mathrm{~cm}$, afastado $2,5 \mathrm{~cm}$ das laterais e $5 \mathrm{~cm}$ da face superior, para a realização dos furos na mesma região de todos os 
blocos. Conforme ilustrado na Figura 2, os furos foram feitos nas duas primeiras linhas do reticulado, garantindo que as amostras fossem coletadas na mesma região de todos os blocos.

O material foi coletado nos intervalos de profundidade de 0-2 mm, 2-5 mm, 5-15 mm e 15-25 mm, sendo acondicionado em saco plástico devidamente identificado. Visando à realização de repetições das leituras da concentração de cloretos, foi coletada uma amostra de $9 \mathrm{~g}$ de material em cada uma das profundidades, possibilitando assim a realização de três leituras.

\section{Análise das amostras}

Para a determinação do teor de cloretos solúveis das amostras coletadas, foi empregada a potenciometria direta, um método de ensaio rápido e de fácil execução, sendo considerado um dos mais adequados para a determinação de cloretos em solução. Essa técnica requer calibração prévia através de soluções aquosas com concentrações de cloreto conhecidas.

Nesta pesquisa foi utilizado o equipamento CL-2000 da NDT James Instruments, que abrange vasta gama de concentrações. A análise nesse equipamento consiste em diluir $3 \mathrm{~g}$ da amostra de concreto em pó em $20 \mathrm{ml}$ de líquido de extração fornecido pelo fabricante, de forma que os íons cloreto reajam com o líquido de extração em uma reação eletroquímica e, através da inserção de um eletrodo com sensor de temperatura, se realize a medição da reação. De acordo com o fabricante, o líquido de extração pode ser substituído por água deionizada. Dessa forma, devido à praticidade e ao menor custo, optou-se pela utilização dessa alternativa na determinação do teor de cloretos das amostras desta pesquisa. É importante destacar que, quando se utiliza o líquido de extração, se determina o teor de cloretos totais da amostra; e, quando a água deionizada é utilizada, é determinado apenas o teor de cloretos livres, aqueles solúveis em água.

Como o fabricante do equipamento CL-2000 não definiu quais as características que a água deionizada deveria apresentar para a utilização no ensaio de determinação do teor de cloretos, tomou-se como base a norma D 1193 (AMERICAN..., 1999), a qual estabelece requisitos para a água adequada para análises químicas. Essa norma estabelece requisitos para quatro categorias, sendo utilizado neste trabalho, como critério de aceitação, o valor de condutividade elétrica estabelecido para a água do Tipo 4, sendo esse de no máximo $5,0 \mu \mathrm{S} / \mathrm{cm}$ a $25^{\circ} \mathrm{C}$. Dessa forma, após submeter a água ao processo de deionização, foi medida a sua condutividade elétrica para avaliar se o valor estava no limite máximo citado, indicando se a água poderia ser utilizada no ensaio ou deveria ser descartada. O deionizador utilizado era da marca Union e possuía capacidade de $100 \mathrm{~L} / \mathrm{h}$, sendo o condutivímetro empregado para a leitura da condutividade elétrica o modelo AB30 da Fisher Scientific.

Tabela 6 - Estação meteorológica que forneceu os dados para a caracterização ambiental de Tramandaí

\begin{tabular}{c|c|c|c}
\hline Estação meteorológica & Cidade & Latitude & Longitude \\
\hline EMet1 & Tramandaí & $30^{\circ} 00^{\prime} 37^{\prime} \mathrm{S}$ & $50^{\circ} 08^{\prime} 09^{\prime} \mathrm{W}$ \\
\hline
\end{tabular}

Figura 2 - Reticulado para a extração das amostras

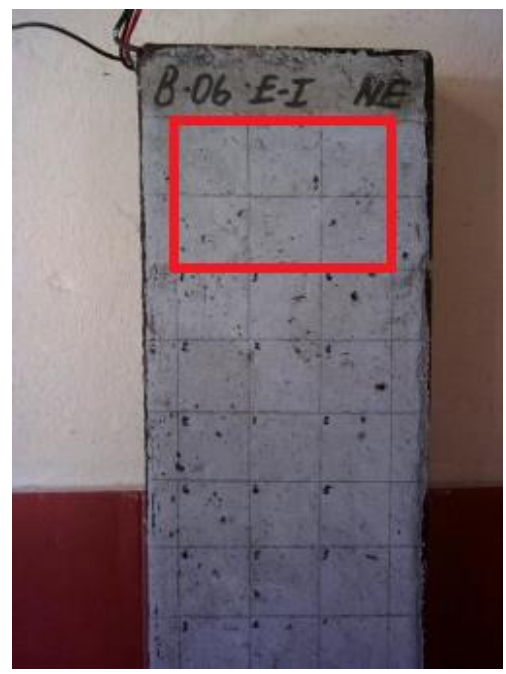

Fonte: adaptada de Romano (2009).

106 Silvestro, L.; Romano, F. S.; Dal Molin, D. C. C. 
Inicialmente foi realizada a calibração do equipamento CL-2000 da NDT James Instruments mediante a utilização dos frascos com líquidos para calibração fornecidos pelo fabricante, os quais apresentam concentração de cloretos de $0,005 \%, 0,01 \%, 0,05 \%, 0,1 \%$ e $0,3 \%$.

Isso posto, efetuou-se a determinação do teor de cloretos solúveis das amostras, através do procedimento descrito a seguir:

(a) pesagem de $3 \mathrm{~g}$ da amostra na forma pulverulenta;

(b) diluição da amostra de $3 \mathrm{~g}$ em $20 \mathrm{ml}$ de água deionizada;

(c) mistura da solução por 1 min em um agitador magnético, modelo 752A da Fisatom, mantendo a velocidade constante em todas as análises realizadas;

(d) espera de 1 min para a solução estabilizar, conforme recomendação do fabricante;

(e) inserção do eletrodo na solução, aguardando 1 min para a realização da leitura. Nesta etapa evitou-se que o eletrodo entrasse em contato com as partículas sólidas da amostra que se depositavam no fundo do recipiente, uma vez que, de acordo com o fabricante, tal contato poderia riscar o eletrodo e danificá-lo; e

(f) lavagem do eletrodo com água deionizada e secagem com papel-toalha para a realização de novas leituras.

O procedimento utilizado para a determinação da concentração de cloretos dos blocos de concreto consiste no mesmo método utilizado por Romano (2009) para a determinação do perfil de cloretos desses blocos com tempos de exposição de 240 dias, possibilitando a comparação dos resultados.

\section{Resultados e discussões}

\section{Caracterização dos concretos}

$\mathrm{Na}$ Tabela 7 são apresentados os resultados de resistência à compressão aos 3, 7 e 28 dias dos concretos CP V, CP V_5SA e CP V_10SA quanto a relações a/agl de 0,45, 0,55 e 0,65. Verifica-se que a incorporação da sílica ativa contribuiu para resultados de resistência à compressão mais elevados.

\section{Caracterização ambiental da estação de monitoramento}

Nas Figuras 3 e 4 são apresentados os valores da temperatura média mensal e umidade relativa média mensal da estação meteorológica de Tramandaí entre setembro de 2008 e outubro de 2017. Os dados evidenciam a elevada variação climática da região, principalmente no tocante às temperaturas médias mensais.

Já os dados anuais referentes à caracterização ambiental da estação meteorológica de Tramandaí são apresentados na Tabela 8. Esses dados indicam que no período de exposição dos blocos de concreto, de setembro de 2008 a outubro de 2017 , a temperatura média anual foi de $19,6{ }^{\circ} \mathrm{C}$, a temperatura mínima anual de $4,4{ }^{\circ} \mathrm{C}$ e a temperatura máxima anual de $34,4{ }^{\circ} \mathrm{C}$, enquanto a umidade relativa média foi de $80,4 \%$. Em relação aos ventos, a velocidade média anual foi de $4,5 \mathrm{~m} / \mathrm{s}$ e a direção predominante a nordeste (NE).

Tabela 7 - Resultados da resistência à compressão axial

\begin{tabular}{c|c|c|c|c}
\hline \multirow{2}{*}{ Traço } & \multirow{2}{*}{$\begin{array}{l}\text { Idade } \\
\text { (dias) }\end{array}$} & \multicolumn{3}{|c}{ Resistência à compressão axial média (fc) } \\
\cline { 3 - 5 } & 3 & $\mathbf{a} / \mathbf{a g l}=\mathbf{0 , 4 5}$ & $\mathbf{a} / \mathbf{a g l}=\mathbf{0 , 5 5}$ & $\mathbf{a} / \mathbf{a g l}=\mathbf{0 , 6 5}$ \\
\hline \multirow{3}{*}{ CP V } & 7 & 28,15 & 20,39 & 14,85 \\
& 28 & 38,90 & 28,53 & 21,06 \\
& 3 & 28,57 & 34,35 & 30,76 \\
\hline \multirow{3}{*}{ CP V_5SA } & 7 & 37,03 & 36,63 & 16,22 \\
& 28 & 52,17 & 39,82 & 22,96 \\
& 3 & 33,33 & 23,38 & 32,48 \\
\hline \multirow{3}{*}{ CP V_10SA } & 7 & 38,59 & 31,25 & 20,74 \\
& 28 & 53,26 & 46,06 & 39,64 \\
\hline
\end{tabular}

Fonte: Romano (2009). 
Figura 3 - Temperatura média mensal da estação meteorológica localizada em Tramandaí entre setembro de 2008 e outubro de 2017

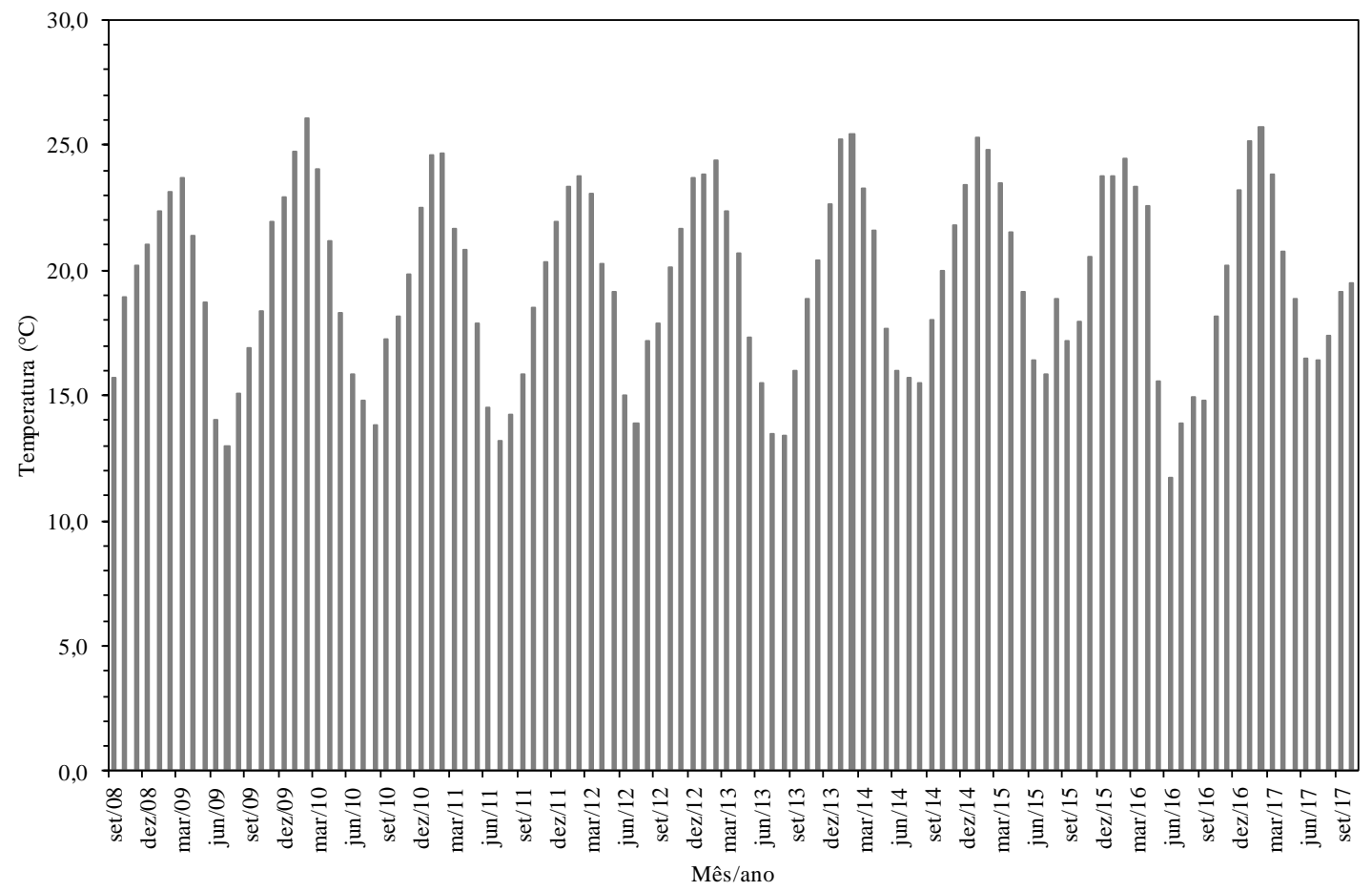

Fonte: Instituto Nacional de Meteorologia (2017).

Figura 4 - Umidade relativa média mensal da estação meteorológica localizada em Tramandaí entre setembro de 2008 e outubro de 2017

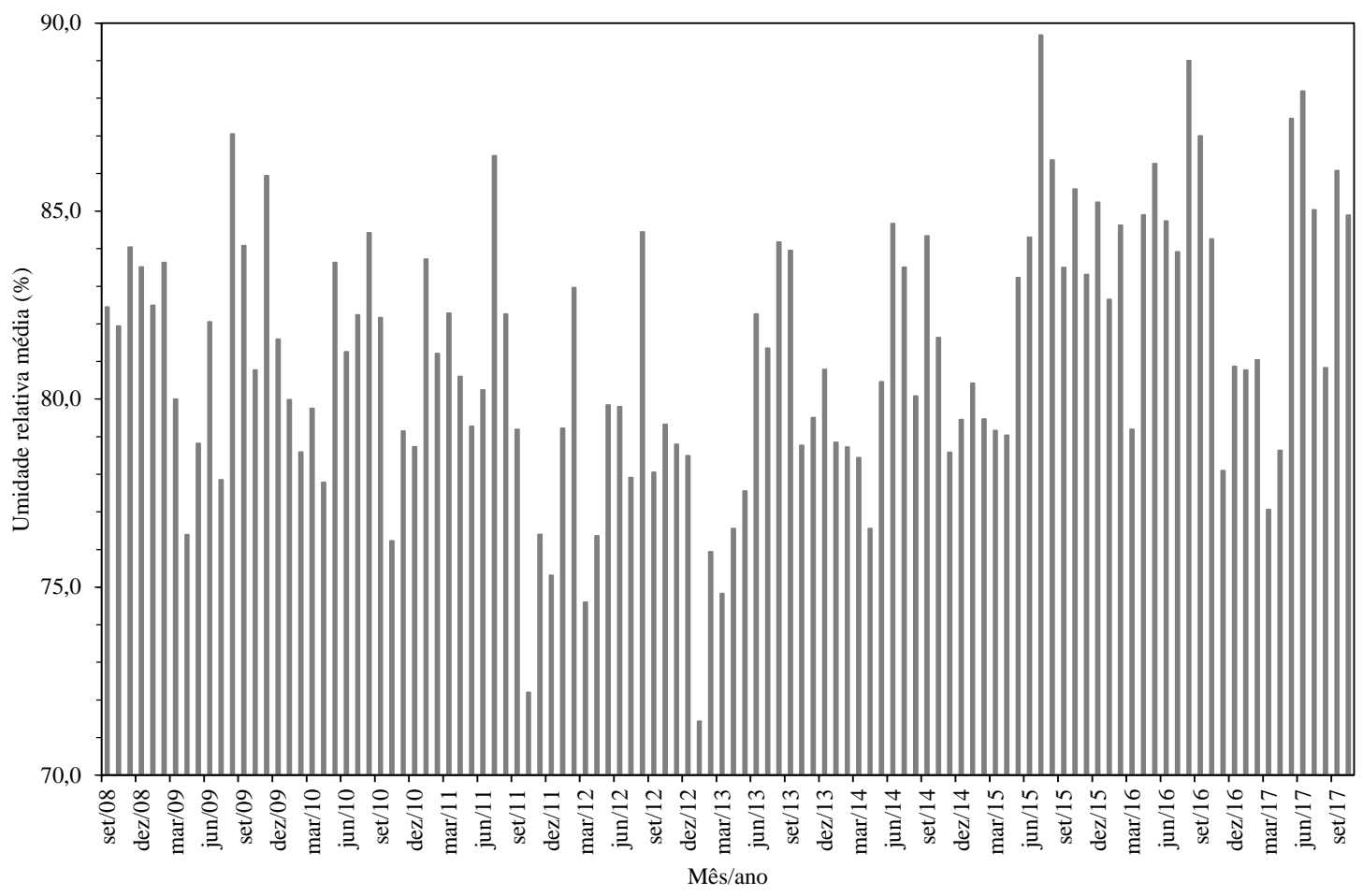

Fonte: Instituto Nacional de Meteorologia (2017).

108 Silvestro, L.; Romano, F. S.; Dal Molin, D. C. C. 
Tabela 8 - Caracterização ambiental da estação meteorológica localizada em Tramandaí

\begin{tabular}{c|c|c|c|c|c|c|c}
\hline Ano & $\begin{array}{c}\text { Temperatura } \\
\text { média anual } \\
\left({ }^{\circ} \mathbf{C}\right)\end{array}$ & $\begin{array}{c}\text { Temperatura } \\
\text { mínima } \\
\text { anual }\left({ }^{\circ} \mathbf{C}\right)\end{array}$ & $\begin{array}{c}\text { Temperatura } \\
\text { máxima anual } \\
\left({ }^{\circ} \mathbf{C}\right)\end{array}$ & $\begin{array}{c}\text { Umidade } \\
\text { relativa } \\
\text { média }(\boldsymbol{\%})\end{array}$ & $\begin{array}{c}\text { Velocidade } \\
\text { média do } \\
\text { vento }(\mathbf{m} / \mathbf{s})\end{array}$ & $\begin{array}{c}\text { Direção } \\
\text { predominante } \\
\text { do vento }\end{array}$ & $\begin{array}{c}\text { Precipitação } \\
\text { acumulada } \\
(\mathbf{m m})\end{array}$ \\
\hline 2008 & 19,0 & 8,8 & 30,8 & 83,0 & 4,8 & $\mathrm{NE}$ & $1.400,8$ \\
2009 & 19,3 & 1,5 & 32,9 & 81,7 & 4,6 & $\mathrm{NE}$ & $1.410,0$ \\
2010 & 19,7 & 5,0 & 38,6 & 80,3 & 4,7 & $\mathrm{NE}$ & $1.681,6$ \\
2011 & 19,1 & 3,4 & 32,5 & 76,2 & 4,6 & $\mathrm{NE}$ & $1.199,2$ \\
2012 & 19,9 & 2,4 & 33,8 & 79,1 & 4,5 & $\mathrm{NE}$ & $1.169,6$ \\
2013 & 19,0 & 3,8 & 35,9 & 78,9 & 4,2 & $\mathrm{NE}$ & $1.593,2$ \\
2014 & 20,3 & 4,4 & 37,3 & 80,4 & 4,3 & $\mathrm{NE}$ & $1.702,0$ \\
2015 & 20,2 & 6,3 & 33,3 & 81,0 & 4,2 & $\mathrm{NNE}$ & $1.925,8$ \\
2016 & 19,6 & 4,7 & 35,1 & 80,9 & 4,3 & $\mathrm{NE}$ & $1.396,2$ \\
2017 & 20,3 & 3,4 & 33,7 & 80,7 & 4,4 & $\mathrm{NE}$ & $1.271,8$ \\
Média & 19,6 & 4,4 & 34,4 & 80,2 & 4,5 & - & - \\
\hline
\end{tabular}

Fonte: Instituto Nacional de Meteorologia (2017).

Na Figura 5 são apresentados os dados de precipitação entre outubro de 2016 e outubro de 2017 do local de exposição dos blocos de concreto, uma vez que o perfil de cloretos com tempo de exposição de 9 anos foi determinado nesse período.

\section{Perfil de cloretos}

Os perfis de concentração de cloretos dos blocos expostos em Tramandaí, após 9 anos, serão apresentados nos subitens a seguir. Inicialmente, com o intuito de verificar a influência dos fatores controláveis na penetração de cloretos, foi aplicada ao estudo uma análise de variância (ANOVA), sendo os fatores denominados de:

(a) A - teor de sílica ativa;

(b) B - relação a/agl; e

(c) $\mathrm{C}$ - profundidade em relação à superfície do concreto.

Foram realizadas três leituras da concentração de cloretos para cada profundidade. Contudo, a partir de uma análise preliminar dos dados, optou-se pela exclusão da leitura com a maior diferença em relação à média. Dessa forma, a análise estatística foi realizada considerando apenas duas leituras. Por fim, cita-se que foi estabelecido um nível de significância de 5\% como critério de decisão.

Na Tabela 9 são apresentados os resultados encontrados na análise de variância aplicada aos perfis de cloretos dos blocos de concreto expostos em Tramandaí por um período de 9 anos. Verificou-se que os três fatores controláveis principais exercem influência significativa na variável de resposta analisada, bem como todas as interações entre tais fatores.

Os resultados encontrados corroboram aqueles identificados por outros pesquisadores, constatando-se que, no geral, a concentração de cloretos tende a diminuir com o aumento da profundidade em relação à superfície do concreto (VIEIRA et al., 2018; WANG et al., 2018). Contudo, é importante destacar que em alguns casos o perfil de cloretos pode apresentar um pico, dado que a camada superficial do material é usualmente exposta a molhamento e evaporação subsequente, ocasionados pela chuva, e que, nessa estreita região, o mecanismo de transporte dos cloretos não é dominado pela difusão (LIU et al., 2017).

Na Figura 6 são apresentados os perfis de cloretos dos concretos CP V, CP V_5SA e CP V_10SA que permaneceram expostos em Tramandaí, em zona de atmosfera marinha, por um período de 9 anos.

Inicialmente, destaca-se que, em decorrência do período de exposição e da distância desses blocos em relação ao mar $(100 \mathrm{~m})$, foram observadas concentrações de cloretos bastante expressivas. Nesse contexto, a norma NBR 12655 (ABNT, 2015), em função da classe de agressividade a que a estrutura está submetida, determina o teor máximo de cloretos permitido. Para concreto armado em brandas condições de exposição, o teor máximo de cloretos é de $0,4 \%$ em relação à massa de cimento. Para concreto não exposto a cloretos, de $0,3 \%$. Já para concretos expostos a cloretos em classes de agressividade forte ou muito forte, o máximo teor de cloretos permitido é de $0,15 \%$ em relação à massa de cimento. Isso posto e considerando os valores apresentados na Figura 6, alguns dos traços avaliados na pesquisa não atendem ao requisito especificado 
pela NBR 12655 (ABNT, 2015) para estruturas de concreto expostas a cloretos em classe de agressividade forte ou muito forte.

Embora a concentração de cloretos que ocasiona a despassivação das armaduras, usualmente denominada de concentração crítica de cloretos, seja função das características do material e das condições de exposição, alguns modelos de previsão de vida útil adotam o valor de $0,4 \%$ de cloretos em relação à massa de cimento (ANDRADE, 2001; BOB, 1996). Nessa conjuntura, é pertinente levar em consideração a norma de desempenho NBR 15575 (ABNT, 2013), que determina uma vida útil de projeto mínima de 50 anos para os sistemas estruturais de edificações habitacionais. Diante disso, alguns traços avaliados nesta pesquisa, com apenas 9 anos de exposição, já apresentaram concentração de cloretos próxima do limite crítico para a despassivação das armaduras em profundidades iguais ou até mesmo superiores a $15 \mathrm{~mm}$, o que pode indicar que essas possivelmente poderão apresentar problemas em relação ao atendimento da vida útil estabelecida pelas normativas brasileiras.

Figura 5 - Precipitação acumulada mensal da estação meteorológica localizada em Tramandaí entre outubro de 2016 e outubro de 2017

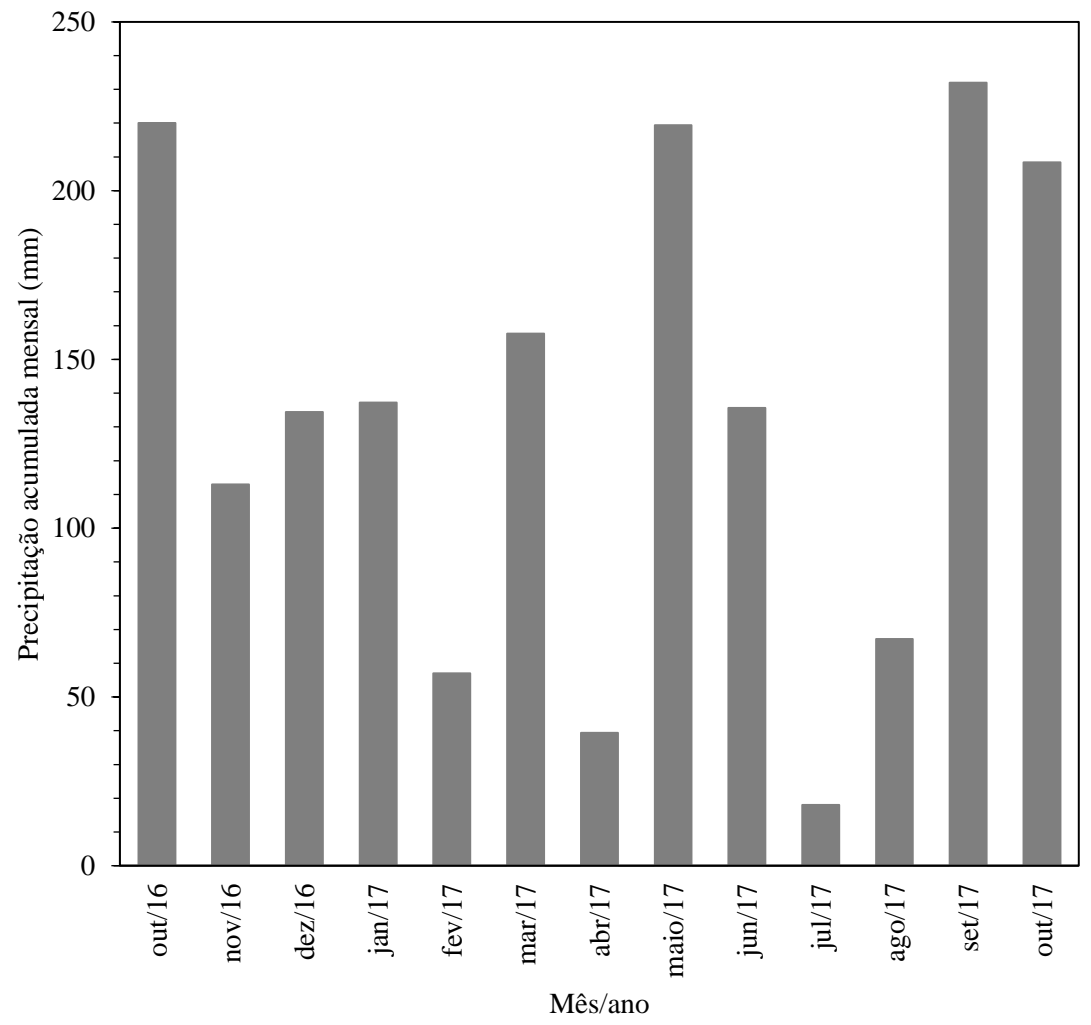

Fonte: Instituto Nacional de Meteorologia (2017).

Tabela 9 - Análise estatística dos dados de concentração de cloretos dos blocos de concreto expostos em Tramandaí por um período de 9 anos

\begin{tabular}{c|c|c|c|c|c|c}
\hline Fonte & SQ & GDL & MQ & Teste F & Probabilidade & Comentário \\
\hline A - Teor de sílica ativa & 0,038538 & 2 & 0,019269 & 264,684095 & $0,00000000 \%$ & $\mathrm{~S}$ \\
B - Relação a/agl & 0,002877 & 2 & 0,001439 & 19,761423 & $0,00016145 \%$ & $\mathrm{~S}$ \\
C - Profundidade & 0,049881 & 3 & 0,016627 & 228,392268 & $0,00000000 \%$ & $\mathrm{~S}$ \\
AB & 0,028137 & 4 & 0,007034 & 96,624025 & $0,00000000 \%$ & $\mathrm{~S}$ \\
AC & 0,016505 & 6 & 0,002751 & 37,786317 & $0,00000000 \%$ & $\mathrm{~S}$ \\
BC & 0,067805 & 6 & 0,011301 & 155,232584 & $0,00000000 \%$ & $\mathrm{~S}$ \\
ABC & 0,079624 & 12 & 0,006635 & 91,145061 & $0,00000000 \%$ & $\mathrm{~S}$ \\
Erro & 0,002621 & 36 & 0,000073 & & & \\
\hline Total & \multicolumn{7}{|l}{} & & & \\
\hline
\end{tabular}

110 Silvestro, L.; Romano, F. S.; Dal Molin, D. C. C. 
Figura 6 - Perfis de cloretos com tempo de exposição de 9 anos dos concretos CP V, CP V_5SA e CP V_10SA

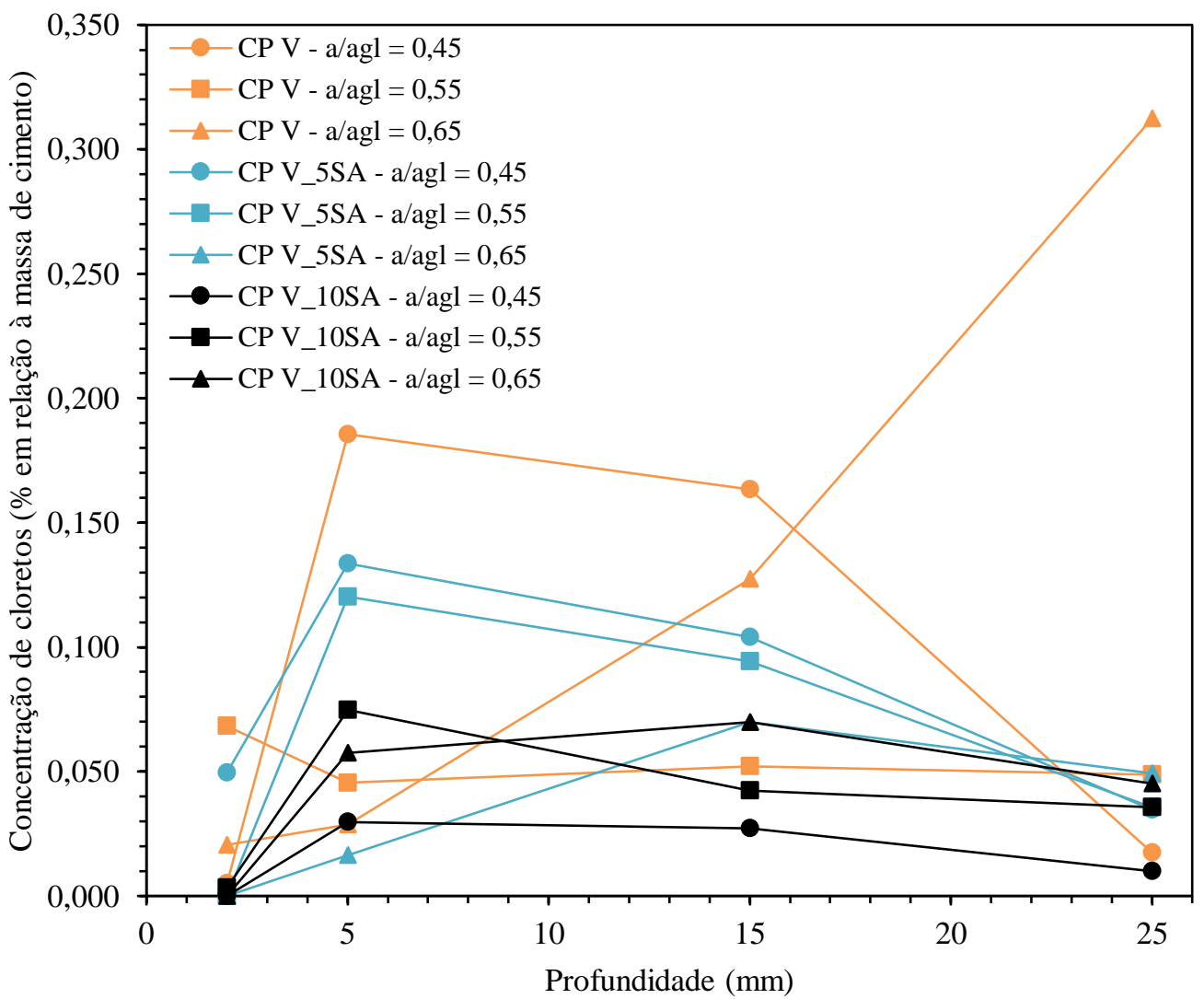

Nesse contexto, reitera-se a importância de dados de penetração de cloretos em condições naturais de exposição, visando a sua utilização para a validação e o ajuste de modelos de previsão de vida útil. Isso auxiliará engenheiros e projetistas a garantir a vida útil de projeto exigida pelas normativas brasileiras e permitirá avaliar a influência dos diversos parâmetros de projeto na vida útil dessas estruturas, tais como tipo de cimento, relação a/agl, resistência à compressão, entre outros. E, por fim, auxiliará no cálculo do tempo remanescente da vida útil de estruturas de concreto, possibilitando a realização de intervenções e manutenções preventivas que assegurem a durabilidade de tais estruturas.

É possível observar que, de maneira geral, os concretos com relação a/agl = 0,45 apresentaram um pico na concentração superficial de cloretos e, em profundidades maiores, concentrações inferiores. Romano (2009) também observou esse comportamento nos perfis desses blocos com tempos de exposição de 45, 105 e 240 dias, justificando que concretos com baixa relação a/agl possuem um maior volume de pasta, o que leva a uma maior absorção superficial. De acordo com Tadayon, Shekarchi e Tadayon (2016), esse comportamento é característico de concretos menos permeáveis, em que o teor de cloretos é maior na região superficial e tende a ser relativamente inferior em maiores profundidades.

Em relação à concentração de cloretos em profundidades maiores $(25 \mathrm{~mm})$, fica clara a maior penetração desses íons em concretos com relações a/agl mais elevadas. Avaliando a concentração de cloretos na profundidade de $25 \mathrm{~mm}$, os concretos moldados com cimento $\mathrm{CP} V$ e relações a/agl = 0,45, 0,55 e 0,65 apresentaram concentração de $0,017 \%, 0,049 \%$ e $0,312 \%$ de cloretos em relação à massa de cimento, respectivamente. Para os concretos CP V_5SA, os valores encontrados foram de $0,035 \%, 0,036 \%$ e $0,049 \%$. E, para os concretos CP V_10SA, os valores foram de 0,010\%, 0,036\% e 0,045\%.

No tocante à utilização de sílica ativa, observa-se que, no geral, teores de adição em torno de 5\% a $10 \%$ promovem uma redução na penetração de cloretos. Essa constatação pode ser observada através da análise da concentração total de cloretos de cada concreto, resultado da soma dos valores nas quatro profundidades avaliadas. Para os concretos com relação a/agl $=0,45$, a utilização do percentual de sílica ativa de $5 \%$ reduziu a concentração total de cloretos em aproximadamente $13 \%$ e a incorporação do teor de sílica ativa 
de $10 \%$ ocasionou a redução de $82 \%$ na concentração total de cloretos. Para os concretos com relação a/agl $=0,55$, verificaram-se aumento de $16 \%$ para o concreto com CP V_5SA e redução de $27 \%$ para o concreto moldado com CP V_10SA. Por fim, para os concretos com relação a/agl $=0,65$, foram observadas reduções de $72 \%$ e $64 \%$ na concentração total de cloretos dos concretos com $5 \%$ e $10 \%$ de sílica ativa em relação ao concreto moldado com o cimento $\mathrm{CP} \mathrm{V}$.

Nesse contexto, diversos autores reportaram uma redução na penetração de cloretos com a incorporação de sílica ativa (AGUIRRE-GUERRERO; MEJÍA-DE-GUTIÉRREZ; MONTÊS-CORREIA, 2016; FARAHANI; TAGHADDOS; SHEKARCHI, 2015). Isso ocorre porque a sílica ativa promove o melhoramento e o refinamento da microestrutura da matriz cimentícia e, assim, contribui para reduzir o ingresso de cloretos no interior dos blocos de concreto. Tadayon, Shekarchi e Tadayon (2016) verificaram uma redução no coeficiente de difusão de aproximadamente $67 \%$ entre o concreto de referência, moldado apenas com cimento Portland, e o concreto com teor de substituição do cimento por sílica ativa de 5\%. Ambos os concretos possuíam relação a/c $=0,40$ e permaneceram expostos por um período de 27 meses em zona de variação de maré na Ilha Qeshm, situada no Golfo Pérsico. Esse comportamento pode ser justificado pela elevada reatividade da sílica ativa, que acelera o processo de hidratação do cimento e, em função da pequena dimensão de suas partículas, é responsável pelo refinamento dos poros da matriz cimentícia e pela redução da porosidade do material (SIDDIQUE; KHAN, 2011). Destaca-se ainda a ação pozolânica desse tipo de adição, que também contribuiu para os resultados encontrados.

Em relação à substituição parcial do cimento por sílica ativa, Selvaraj, Muralidharan e Srinivasan (2003) citam que a incorporação dessa adição é responsável pelo refinamento da microestrutura do concreto em função de dois mecanismos principais. O primeiro mecanismo está associado ao efeito físico da sílica, que promove o preenchimento dos poros da matriz cimentícia. Já o segundo mecanismo é decorrente da ação química da adição e está associado à reação pozolânica que essa apresenta quando reage com o hidróxido de cálcio e forma silicato de cálcio hidratado $(\mathrm{C}-\mathrm{S}-\mathrm{H})$, principal componente responsável pela resistência mecânica de matrizes cimentícias. Isso contribui para a redução na penetração de cloretos, conforme reportado em estudos prévios (PAPADAKIS, 2000; RAMEZANIANPOUR; REZAEI; SAVOJ, 2015; SONG et al., 2007).

O mecanismo de ação da sílica ativa em uma matriz cimentícia pode ser estudado sob três aspectos:

(a) refinamento do tamanho dos poros e densificação da matriz;

(b) reação com o hidróxido de cálcio proveniente das reações de hidratação do cimento; e

(c) refinamento da zona de transição entre a pasta e o agregado.

Nesse contexto, a incorporação de sílica ativa reduz a espessura da zona de transição entre a pasta e o agregado e reduz o grau de orientação dos cristais de portlandita nessa região. Dessa maneira, as propriedades mecânicas e de durabilidade são aperfeiçoadas devido ao melhoramento da zona de transição da matriz cimentícia (KHAN; SIDDIQUE, 2011). Khan e Siddique (2011) reiteram que o mecanismo de ação da sílica ativa não está relacionado apenas à reação pozolânica e à formação de C-S-H, mas também à modificação da microestrutura, ou seja, à orientação, à porosidade e à espessura da zona de transição, conforme previamente mencionado.

De acordo com Mehta e Ashish (2020), os efeitos físicos e químicos da sílica ativa podem promover um aumento significativo da resistência à compressão e, consequentemente, da resistência à penetração de cloretos. As partículas da sílica ativa aumentam o empacotamento dos materiais sólidos, preenchendo os espaços entre as partículas de cimento. Isso porque, usualmente, são constituídas majoritariamente por partículas de tamanho inferior a $1 \mu \mathrm{m}$ e possuem elevada superfície específica. A sílica ativa também induz vários locais de nucleação para a precipitação dos produtos de hidratação do cimento, acelerando as reações de hidratação e formando cristais de portlandita menores (ISAIA; GASTALDINI; MORAIS, 2003).

Algumas pesquisas reportaram que a utilização de sílica ativa ocasiona uma redução na capacidade de fixação de cloretos da pasta de cimento (DOUSTI; SHEKARCHI; TADAYON, 2009; THOMAS et al., 2012). De acordo com Shi et al. (2012), isso ocorre porque a sílica ativa reduz as fases de aluminatos, as responsáveis por tal fixação. Para Yuan et al. (2009), a substituição do cimento Portland por sílica ativa pode levar à redução do $\mathrm{pH}$, o que impacta no aumento da proporção de cloretos livres. Entretanto, mesmo com a menor fixação de cloretos, a adição de sílica ativa reduz a difusão da matriz cimentícia, aumentando a resistência à penetração de cloretos de concretos e argamassas. Beaudoin, Ramanchandran e Feldman (1990) ainda citam que a concentração de cloretos livres em cimentos com sílica ativa é consideravelmente maior 
por causa da baixa relação $\mathrm{Ca} / \mathrm{Si}$ do $\mathrm{C}-\mathrm{S}-\mathrm{H}$ existente nessas pastas, uma vez que o $\mathrm{C}-\mathrm{S}-\mathrm{H}$, em comparação com o formado pela hidratação do cimento, tem menor capacidade de adsorção de cloretos.

É importante mencionar que em regiões de zona de atmosfera marinha, além do ataque por cloretos, ocorre simultaneamente a carbonatação do concreto, a qual ocasiona a redução do pH do material. Quando esse $\mathrm{pH}$ atinge valores inferiores a 9,5, o filme de passivação na superfície das armaduras começa a ser decomposto, o que, aliado a concentrações de cloretos acima do valor crítico, resulta na aceleração dos danos à estrutura de concreto. A redução do pH do concreto também afeta a estabilidade do sal de Friedel, ocasionando a sua dissolução (XIE et al., 2019). Como resultado, há aumento na concentração de cloretos livres, a forma que efetivamente é responsável pela despassivação das armaduras e por prejuízos à durabilidade das estruturas de concreto armado (MOHAMMED; HAMADA, 2003; RIBEIRO et al., 2014).

Nessa conjuntura, Xie et al. (2019) citam que são poucos os estudos existentes que avaliaram a difusão e a distribuição de cloretos em concretos com diferentes graus de carbonatação. Dessa maneira, os autores avaliaram o coeficiente de difusão e o perfil de cloretos de concretos com percentuais de substituição de cimento Portland por cinza volante de $15 \%$ e $30 \%$, após serem submetidos à carbonatação acelerada por 62 dias. Eles observaram que nos estágios iniciais da carbonatação há o refinamento da estrutura de poros internas do concreto, o que melhora a capacidade do material de resistir à difusão dos íons cloreto. Já em estágios mais avançados de carbonatação, verificou-se que os concretos apresentaram estrutura de poros mais grosseira e, consequentemente, redução da resistência à difusão de cloretos, especialmente para os traços compostos de cinza volante e altas relações a/aglomerante $(\mathrm{a} / \mathrm{agl}>0,5)$. Além disso, os autores constataram que a capacidade de fixação de cloretos dos concretos com cinza volante caiu expressivamente nos estágios mais avançados de carbonatação.

Outro aspecto que merece destaque diz respeito ao período de coleta das amostras desta pesquisa. Como pode ser observado na Figura 5, o mês de outubro de 2017 foi caracterizado por elevada precipitação, o que pode ter contribuído para a redução da concentração superficial (Cs) dos concretos. Isso porque, de acordo com Castro-Borges et al. (2013), a chuva tem um efeito denominado de lavagem superficial, que tende a lixiviar a camada externa do concreto, reduzindo a concentração superficial de cloretos nessa região. Nesse âmbito, Meira (2004) expôs concretos moldados com cimento CP IV e CP II - F e relações a/c de 0,5, 0,57 e 0,65 em zona de atmosfera marinha com distâncias de $10 \mathrm{~m}, 100 \mathrm{~m}, 200 \mathrm{~m}$ e $500 \mathrm{~m}$ do mar e mediu a Cs após 6, 10, 14 e 18 meses. O autor verificou que a Cs apresentou um decréscimo entre as medidas realizadas com 14 e 18 meses de exposição, coincidindo com o período de precipitações mais intensas e concentradas, o que leva a crer que a chuva contribuiu para a redução da Cs.

Em relação às oscilações ambientais do local de exposição dos blocos, a umidade relativa entre outubro de 2016 e outubro de 2017 (Figura 4) apresentou variação entre 70\% e 90\%. Nesse sentido, no período de iniciação, quanto maior o teor de umidade ambiental, maior a quantidade de água no interior dos poros, o que favorece a mobilidade dos íons cloreto para o interior do concreto (ANDRADE, 2001; NIELSEN; GEIEKER, 2003). De maneira semelhante, o aumento da temperatura também atua favorecendo o ingresso de cloretos. Como pode ser observado na Figura 3, a temperatura média mensal varia de acordo com o período do ano. Nesse âmbito, é importante levar em consideração a influência da temperatura na liberação de cloretos quimicamente ligados. De acordo com Xu et al. (2016), o aumento da temperatura, no geral, pode liberar parcialmente os cloretos ligados, sendo a quantidade liberada função da relação a/c, da concentração de cloretos total e da faixa de temperatura.

Por fim, efetuou-se a comparação da concentração de cloretos na profundidade de $25 \mathrm{~mm}$ dos perfis com 9 anos de exposição com aqueles determinados por Romano (2009) na idade de 240 dias (aproximadamente 0,7 ano), conforme apresentado na Tabela 10.

Verifica-se um crescimento significativo da concentração de cloretos ao longo do tempo, o que corrobora o comportamento constatado em trabalhos prévios (MEDEIROS JUNIOR et al., 2015; ZHANG et al., 2018; ZHU et al., 2016). Esse aumento é maior conforme o aumento da relação a/agl, o que evidencia a grande influência desse fator na durabilidade de estruturas de concreto armado. De maneira análoga, a adição de sílica ativa também contribui para a mitigação da penetração de cloretos, uma vez que reduziu significativamente o aumento do teor de cloretos. 
Tabela 10 - Comparação da concentração de cloretos na profundidade de $25 \mathrm{~mm}$ dos perfis de cloretos com 9 e 0,7 ano de exposição

\begin{tabular}{l|c|c|c|c}
\hline \multirow{2}{*}{ Aglomerante } & \multirow{2}{*}{$\begin{array}{c}\text { Relação } \\
\text { a/agl }\end{array}$} & \multicolumn{3}{|c}{$\begin{array}{c}\text { Concentração de cloretos (\% } \\
\text { em relação à massa de cimento) }\end{array}$} \\
\cline { 3 - 5 } & & $\mathbf{0 , 7}$ ano & $\mathbf{9}$ anos & Aumento \\
\hline \multirow{3}{*}{ CP V } & 0,45 & 0,009 & 0,017 & $192,4 \%$ \\
& 0,55 & 0,012 & 0,049 & $406,4 \%$ \\
& 0,65 & 0,015 & 0,312 & $2.082,6 \%$ \\
\hline \multirow{2}{*}{ CP V_5SA } & 0,45 & 0,009 & 0,035 & $384,8 \%$ \\
& 0,55 & 0,011 & 0,036 & $325,1 \%$ \\
& 0,65 & 0,013 & 0,049 & $379,4 \%$ \\
\hline \multirow{3}{*}{ CP V_10SA } & 0,45 & 0,009 & 0,010 & $109,9 \%$ \\
& 0,55 & 0,011 & 0,036 & $325,1 \%$ \\
& 0,65 & 0,013 & 0,045 & $347,8 \%$ \\
\hline
\end{tabular}

\section{Considerações finais}

A pesquisa avaliou a concentração de cloretos em concretos expostos por 9 anos em zona de atmosfera marinha na cidade de Tramandaí. Os resultados obtidos indicaram que

(a) no tocante à utilização de sílica ativa, observa-se que, no geral, teores de adição em torno de 5\% a $10 \%$ promovem uma redução na penetração de cloretos;

(b) no que diz respeito à influência da relação a/agl na penetração de cloretos, nota-se que concretos menos permeáveis $(\mathrm{a} / \mathrm{agl}=0,45)$ tendem a apresentar teores de cloretos maiores na região superficial e valores relativamente inferiores em maiores profundidades. Verifica-se também que, quanto maior a relação a/agl, maior a concentração de cloretos em profundidades maiores; e

(c) a redução da relação a/agl e a incorporação de sílica ativa mostraram ser medidas eficazes na redução da concentração de cloretos ao longo do tempo.

Isso posto, o artigo evidencia a importância da obtenção de dados de concentração de cloretos em concretos expostos em ambiente natural, visto que ensaios acelerados apresentam uma boa aplicação para a comparação do desempenho de diferentes materiais. Contudo, no que se refere ao real comportamento e estimativa da vida útil de estruturas de concreto, dados reais, como os obtidos nesta pesquisa, são mais adequados, apesar de demandarem períodos de exposição mais longos. Além disso, o trabalho ressalta a importância de fatores como a relação a/agl e a utilização de materiais cimentícios suplementares, como a sílica ativa, na durabilidade de tais estruturas.

\section{Referências}

AGUIRRE-GUERRERO, A. M.; MEJÍA-DE-GUTIÉRREZ, R.; MONTÊS-CORREIA, M. J. R. Corrosion performance of blended concretes exposed to diferente aggressive environments. Construction and Building Materials, v. 121, p. 704-716, 2016.

AMERICAN NATIONAL STANDARD FEDERAL TEST METHOD. D 1193: standard specification for reagent water. West Conshohocken, 1999.

ANDRADE, J. J. O. Contribuição à previsão de vida útil de estruturas de concreto armado atacadas pela corrosão de armaduras: iniciação por cloretos. Porto Alegre, 2001. 277 f. Tese (Doutorado em Engenharia Civil) - Programa de Pós-Graduação em Engenharia Civil, Universidade Federal do Rio Grande do Sul, Porto Alegre, 2001.

ASSOCIAÇÃO BRASILEIRA DE NORMAS TÉCNICAS. NBR 12655: concreto de cimento Portland: preparo, controle, recebimento e aceitação: procedimento. Rio de Janeiro, 2015.

ASSOCIAÇÃO BRASILEIRA DE NORMAS TÉCNICAS. NBR 15575: parte 1: desempenho de edifícios habitacionais. Rio de Janeiro, 2013.

ASSOCIAÇÃO BRASILEIRA DE NORMAS TÉCNICAS. NBR 5733: cimento Portland de alta resistência inicial. Rio de Janeiro, 1991.

114 Silvestro, L.; Romano, F. S.; Dal Molin, D. C. C. 
ASSOCIAÇÃO BRASILEIRA DE NORMAS TÉCNICAS. NBR 5738: moldagem e cura de corpos de prova cilíndricos ou prismáticos de concreto. Rio de Janeiro, 2003b.

ASSOCIAÇÃO BRASILEIRA DE NORMAS TÉCNICAS. NBR 5739: concreto: ensaio de compressão de corpos-de-prova cilíndricos. Rio de Janeiro, 2007.

ASSOCIAÇÃO BRASILEIRA DE NORMAS TÉCNICAS. NBR NM 248: agregados: determinação da composição granulométrica. Rio de Janeiro, 2003a.

ASSOCIAÇÃO BRASILEIRA DE NORMAS TÉCNICAS. NBR NM 52: agregado miúdo: determinação da massa específica e massa específica aparente. Rio de Janeiro, 2009a.

ASSOCIAÇÃO BRASILEIRA DE NORMAS TÉCNICAS. NBR NM 53: agregado graúdo: determinação da massa específica, massa específica aparente e absorção de água. Rio de Janeiro, 2009 b.

ASSOCIAÇÃO BRASILEIRA DE NORMAS TÉCNICAS. NBR NM 67: concreto: determinação da consistência pelo abatimento do tronco de cone. Rio de Janeiro, 1996.

BEAUDOIN, J. J.; RAMACHANDRAN, V. S.; FELDMAN, R. F. Interaction of chloride and C-S-H. Cement and Concrete Research, v. 20, p. 875-883, 1990.

BOB, C. Probabilistic assessment of reinforcement corrosion in existing structures. In: INTERNATIONAL CONFERENCE: CONCRETE REPAIR, REHABILITATION AND PROTECTION, Dundee, 1996. Proceedings [...] Dundee, 1996.

BRANDÃO, R. M. L. Levantamento das manifestações patológicas nas edificações, com até cinco anos de idade, executadas no estado de Goiás. Goiás, 2007. 224 f. Dissertação (Mestrado em Engenharia Civil) - Escola de Engenharia Civil, Universidade Federal de Goiás, Goiânia, Goiás, 2007.

CASTRO-BORGES, P. et al. Effect of environmental changes on chemical and electrochemical parameters in reinforced concrete: the case of a tropical marine atmosphere. International Journal of Electrochemical Science, v. 8, p. 6204-6211, 2013.

CHALEE, W.; JATURAPITAKKUL, C.; CHINDAPRASIRT, P. Predicting the chloride penetration of fly ash concrete in seawater. Marine Structures, v. 22, p. 341-353, 2009.

DAL MOLIN, D. C. C. et al. Contribuição à previsão da vida útil de estruturas de concreto. In: KAZMIERCZAK, C. S.; FABRÍCIO, M. M. Avaliação de desempenho de tecnologia construtivas inovadoras: materiais e sustentabilidade. Porto Alegre: ANTAC, 2016.

DASAR, A. et al. Deterioration progress and performance reduction of 40-years-old reinforced concrete beams in natural corrosion environments. Construction and Building Materials, v. 149, p. 690-704, 2017.

DOUSTI, A.; SHEKARCHI, M.; TADAYON, M. Effect of silica fume on chloride binding in concrete. In: INTERNATIONAL CONFERENCE ON CONSTRUCTION MATERIALS: PERFORMANCE, INNOVATIONS AND STRUCTURAL IMPLICATIONS, 4., Nagoya, 2009. Proceedings [...] Negoya, 2009.

FARAHANI, A.; TAGHADDOS, H.; SHEKARCHI, M. Prediction of long-term chloride diffusion in silica fume concrete in a marine environment. Cement and Concrete Composites, v. 59, p. 10-17, 2015.

HELENE, P. R. L.; TERZIAN, P. Manual de dosagem e controle do concreto. São Paulo: PINI, 1993.

INSTITUTO BRASILEIRO DE GEOGRAFIA E ESTATÍSTICA. Sobre o Brasil: posição e extensão. Disponível em: http://teen.ibge.gov.br/mao-na-roda/posicao-e-extensao.html. Acesso em: 19 jul. 2017.

INSTITUTO NACIONAL DE METEOROLOGIA. Dados meteorológicos da Estação Meteorológica de Observação de Superfície Automática de Tramandaí A843. 2017.

ISAIA, G. C.; GASTALDINI, A. L. G.; MORAES, R. Physical and pozzolanic action of mineral additions on the mechanical strength of high-performance concrete. Cement and Concrete Composites, v. 25, p. 6976, 2003.

KHAN, M. I.; SIDDIQUE, R. Utilization of silica fume in concrete: review of durability properties. Resources, Conservation and Recycling, v. 57, p. 30-35, 2011.

LIU, J. et al. Chloride transport and microstructure of concrete with/without fly ash under atmospheric chloride condition. Construction and Building Materials, v. 146, p. 493-501, 2017. 
LIU, J. et al. Effects of chlorides ions on carbonation rate of hardened cement paste by X-ray CT techniques. Construction and Building Materials, v.122, p. 619-627, 2016.

MARIC, M. K. et al. Service life prediction of concrete structures in marine environment - case study: Maslenica Motorway Bridge. In: INTERNATIONAL CONFERENCE ON CONSTRUCTION MATERIALS FOR SUSTAINABLE FUTURE, Zadar, 2017. Proceedings [...] Zadar, 2017.

MEDEIROS JUNIOR, R. A. et al. Chloride penetration into concrete in an offshore platform-analysis of exposure conditions. Ocean Engineering, v. 103, p. 78-87, 2015.

MEHTA, A.; ASHISH, D. K. Silica fume and waste glass in cement concrete production: a review. Journal of Building Engineering, v. 29, 2020.

MEIRA, G. R. Agressividade por cloretos em zona de atmosfera marinha frente ao problema da corrosão em estruturas de concreto armado. Florianópolis, 2004. 369 f. Tese (Doutorado em Engenharia Civil) - Programa de Pós-Graduação em Engenharia Civil, Universidade Federal de Santa Catarina, Florianópolis, 2004.

MEIRA, G. R. et al. Chloride penetration into concrete structures in the marine atmosphere zone: relationship between deposition of chlorides on the wet candle and chlorides accumulated into concrete. Cement and Concrete Composites, v. 29, p. 667-676, 2007.

MEIRA, G. R.; FERREIRA, P. Revisão sobre ensaios acelerados para indução da corrosão desencadeada por cloretos em concreto armado. Ambiente Construído, Porto Alegre, v. 19, n. 4, p. 223-248, 2019.

MILANI, C. J.; KRIPKA, M. Diagnosis of pathologies in bridges of the road system in Brazil. Constructii: Journal of Civil Engineering Research, v. 1, p. 26-34, 2012.

MOHAMMED, T. U.; HAMADA, H. Relationship between free chloride and total chloride contents in concrete. Cement and Concrete Research, v. 33, p. 1487-1490, 2003.

MUTHULINGAM, S.; RAO, B. N. Consistent models for estimating chloride ingress parameters in fly ash concrete. Journal of Building Engineering, v. 3, p. 24-38, 2015.

NIELSEN, E. P.; GEIKER, M. R. Chloride diffusion in partially saturated cementitious material. Cement and Concrete Research, v. 33, p. 133-138, 2003.

OH, B. H.; JANG, S. Y. Effects of material and environmental parameters on chloride penetration profiles in concrete structures. Cement and Concrete Research, v. 37, p. 47-53, 2007.

OTIENO, M.; BEUSHAUSEN, H.; ALEXANDER, M. Effect of chemical composition of slag on chloride penetration resistance of concrete. Cement \& Concrete Composites, v. 46, p. 56-64, 2014.

PANG, L.; LI, Q. Service life prediction of RC structures in marine environment using long term chloride ingress data: Comparison between exposure trials and real structures surveys. Construction and Building Materials, v. 113, p. 979-987, 2016.

PAPADAKIS, V. G. Effect of supplementary cementing materials on concrete resistance against carbonation and chloride ingress. Cement and Concrete Research, v. 30, p. 291-299, 2000.

PINTAN, N. M. et al. Pathological manifestations and the study of corrosion present on bridges of the city of Recife. Electronic Journal of Geotechnical Engineering, v. 20, p. 11893-11907, 2015.

PRUCKNER, F.; GJORV, O. E. Effect of $\mathrm{CaCl}_{2}$ and $\mathrm{NaCl}$ additions on concrete corrosivity. Cement and Concrete Research, v. 34, p. 1209-1217, 2004.

RAMEZANIANPOUR, A. A.; REZAEI, H. R.; SAVOJ, H. R. Influence of silica fume on chloride diffusion and corrosion resistance of concrete - A review. Asian Journal of Civil Engineering, v. 16, n. 3, p. 301$321,2015$.

RIBEIRO, D. V. et al. Corrosão em estruturas de concreto armado: teoria, controle e métodos de análise. Rio de Janeiro: Elsevier Brasil, 2014.

ROMANO, F. S. Estudo do ingresso de cloretos em estruturas de concreto no Litoral Norte do Rio Grande do Sul. Porto Alegre, 2009. 153 f. Dissertação (Mestrado em Engenharia Civil) - Programa de PósGraduação em Engenharia Civil, Universidade Federal do Rio Grande do Sul, Porto Alegre, 2009. 
SELVARAJ, R.; MURALIDHARAN, S.; SRINIVASAN, S. The influence of silica fume on the factors affecting the corrosion of reinforcement in concrete: a review. Structural Concrete, n. 1, v. 4, p. 19-24, 2003.

SHI, X. et al. Durability of steel reinforced concrete in chloride environments: an overview. Construction and Building Materials, v. 20, p. 125-138, 2012.

SHODJA, H. M.; KIANI, K.; HASHEMIAN, A. A model for the evolution of concrete deterioration due to reinforcement corrosion. Mathematical and Computer Modelling, v. 52, p. 1403-1422, 2010.

SIDDIQUE, R.; KHAN, M. I. Supplementary cement materials. New York: Springer, 2011.

SILVA, L. K.; CABRAL, A. E. B. Levantamento de manifestações patológicas em estruturas de concreto armado no estado do Ceará. In: ENCONTRO NACIONAL DE TECNOLOGIA DO AMBIENTE CONSTRUÍDO, 15., Maceió, 2014. Anais [...] Maceió: ANTAC, 2014.

SONG, H. et al. An estimation of the diffusivity of silica fume concrete. Building and Environment, v. 42, p. 1358-1367, 2007.

SPIESZ, P.; BROUWERS, H. J. H. The apparent and effective chloride migration coefficients obtained in migration tests. Cement and Concrete Research, v. 48, p. 116-127, 2013.

TADAYON, M. H.; SHEKARCHI, M.; TADAYON, M. Long-term field study of chloride ingress in concretes containing pozzolans exposed to severe marine tidal zone. Construction and Building Materials, v. 123, p. 611-616, 2016.

THOMAS, M. D. A. et al. The effect of supplementary cementitious materials on chloride binding in hardened cement paste. Cement and Concrete Research, v. 42, p. 1-7, 2012.

TORRES-ACOSTA, A. A.; NAVARRO-GUTIERREZ, S.; TERÁN-GUILLÉN, J. Residual flexure capacity of corroded reinforced concrete beams. Engineering Structures, v. 29, p. 1145-1152, 2007.

TUUTTI, K. Corrosion of steel in concrete. Stockholm: Swedish Cement and Concrete Research Institute, 1982.

VALIPOUR, M. et al. In situ study of chloride ingress in concretes containing natural zeolite, metakaolin and silica fume exposed to various exposure conditions in a harsh marine environment. Construction and Building Materials, v. 46, p. 63-70, 2013.

VIEIRA, D. R. et al. Service life modeling of a bridge in a tropical marine environment for durable design. Construction and Building Materials, v. 163, p. 315-325, 2018.

WANG, Y. et al. Prediction model of long-term chloride diffusion into plain concrete considering the effect of the heterogeneity of materials exposed to marine tidal zone. Construction and Building Materials, v. 159, p. 297-315, 2018.

WEERDT, K. et al. Towards the understanding of chloride profiles in marine exposed concrete, impact of leaching and moisture content. Construction and Building Materials, v. 120, p. 418-431, 2016.

XIE, X. et al. Diffusion and distribution of chloride ions in carbonated concrete with fly ash. Construction and Building Materials, v. 218, p. 119-125, 2019.

$\mathrm{XU}$, J. et al. Influence of $\mathrm{CaCl}_{2}$ and $\mathrm{NaCl}$ from different sources on chloride threshold value for the corrosion of steel reinforcement in concrete. Construction and Building Materials, v. 25, p. 663-669, 2011.

$\mathrm{XU}$, J. et al. Influence of elevated temperature on release of bound chlorides from chloride-admixed plain and blended cement pastes. Cement and Building Materials, v. 104, p. 9-15, 2016.

YILDIRIM, H.; ILICA, T.; SENGUL, O. Effect of cement type on the resistance of concrete against chloride penetration. Construction and Building Materials, v. 25, p. 1282-1288, 2011.

YUAN, Q. et al. Chloride binding of cement-based materials subjected to external chloride environment: a review. Construction and Building Materials, p. 1-13, 2009.

ZHANG, J. et al. Instantaneous chloride diffusion and its time dependency of concrete exposed to a marine tidal environment. Construction and Building Materials, v. 167, p. 225-234, 2018. 
ZHU, W. et al. Influence of long-term chloride diffusion in concrete and the resulting corrosion of reinforcement on the serviceability of RC beams. Cement and Concrete Composites, v. 71, p. 144-152, 2016.

\section{Laura Silvestro}

Laboratório de Aplicações de Nanotecnologia em Construção Civil | Universidade Federal de Santa Catarina | Rua João Pio Duarte, s/n, Córrego Grande | Florianópolis - SC - Brasil | CEP 88040-367 | Tel.: (48) 3721-4980 | E-mail: laurasilvestro@ymail.com

\section{Fátima Sequeira Romano}

Superintendência de Infraestrutura | Universidade Federal do Rio Grande do Sul | Av. Paulo Gama, 110, Farroupilha | Porto Alegre - RS Brasil | CEP 90840-440 | Tel.: (51) 3308-3619 | E-mail: fatima.romano@progesp.ufrgs.br

\section{Denise Carpena Coitinho Dal Molin}

Núcleo Orientado para a Inovação na Construção | Universidade Federal do Rio Grande do Sul | Av. Osvaldo Aranha, 99, Centro Histórico | Porto Alegre - RS - Brasil | Tel.: (51) 3308-3518 | E-mail: dmolin@ufrgs.br

\section{Ambiente Construído}

Revista da Associação Nacional de Tecnologia do Ambiente Construído Av. Osvaldo Aranha, $99-3^{\circ}$ andar, Centro

Porto Alegre - RS - Brasil CEP 90035-190

Telefone: +55 (51) 3308-4084

Fax: +55 (51) 3308-4054

www.seer.ufrgs.br/ambienteconstruido

E-mail: ambienteconstruido@ufrgs.br 